\title{
CHARACTERIZATION OF A REHYDRATION PHENOMENON IN CEMENT- BASED MATERIALS CONTAINING HEAT-INDUCED CRACKS: COUPLED TRANSPORT PROPERTIES AND X-RAY MICRO-TOMOGRAPHY
}

\author{
YAN PEI $^{*, 2}$, FREDERIC SKOCZYLAS ${ }^{\dagger, 2}$ AND GRÉGORY HAUSS ${ }^{\dagger \dagger}$ \\ * Laboratoire de Mécanique de Lille (LML) and Ecole centrale de Lille, \\ BP48, F-59651 Villeneuve d'Ascq Cedex, France \\ ${ }^{2}$ College of Civil Engineering and Architecture, Hubei University of Technology, Wuhan, China \\ E-mail: yan.pei@ec-lille.fr \\ ' Laboratoire de Mécanique de Lille (LML) and Ecole centrale de Lille, \\ BP48, F-59651 Villeneuve d'Ascq Cedex, France \\ ${ }^{2}$ College of Civil Engineering and Architecture, Hubei University of Technology, Wuhan, China \\ E-mail: frederic.skozylas@ec-lille.fr \\ ${ }^{\dagger \dagger}$ Laboratoire de Mécanique de Lille(LML) and Université Lille1-Sciences et Technologies, \\ Cité Scientifique, 59650 Villeneuve d'Ascq Cedex, France \\ E-mail: gregory.hauss@uni-lille. fr
}

Key words: Cement-based materials, Heat-induced cracks, Rehydration, Permeability, CT

\begin{abstract}
This study deals with the phenomenon of rehydration in heat-induced macro/micro cracks for a normalized mortar and concrete paste, both having a W/C ratio of 50\%. Reyhydration was tested using steady state gas (argon) and ethanol permeability measurements provided by our laboratory, combined with thermo-gravimetric (ATG) and micro-tomographic (CT) analyses. Prior to these experiments, all of the samples were subjected to successive heating-cooling cycles, from a $105^{\circ} \mathrm{C}$ reference state, up to $600^{\circ} \mathrm{C}$. At the macroscopic level, the material's transport properties are determined by means of gas permeability tests, following which the same sample is measured using the ethanol permeability test (after saturation in distilled water and drying at $105^{\circ} \mathrm{C}$ ). At the microscopic level, the pore network of the heat-treated cement pastes is characterized using CT (voxel $\approx 4 \mu \mathrm{m}$ ), before and after rehydration in order to assess its 3D profile. This includes quantitative analysis of the crack size, the connected and non-connected pore volume, the pore surface area, as well as the pores' distribution. The self-healing capacity of saturated heat-treated cement-based materials is clearly revealed, when these results are combined with ATG analyses of the material's mineralogical composition.
\end{abstract}

The results show that following heat-treatment, the gas permeability of mortars is of the order of $10^{-15} \mathrm{~m}^{2}$ at $600^{\circ} \mathrm{C}$, whereas following rehydration, their ethanol permeability lies in the range between $10^{-18}$ and $10^{-17} \mathrm{~m}^{2}$, which is quite close to the intact gas permeability of mortar at $105^{\circ} \mathrm{C}$. 
This behavior corresponds primarily to that of self-healing products penetrating heat-treated cracks. During the preceding gas permeability cycle, an increase in confining pressure also contributes to the irreversible closure of cracks. Finally, the results of the ATG, CT, and permeability (gas, ethanol) tests, all of which reveal a rehydration phenomenon occurring in heat-induced cracks, are found to be well correlated.

\section{INTRODUCTION}

This broad experimental study was carried out in laboratory, and investigated the hydraulic mechanics and autogenous selfhealing behaviours of cement-based materials following a slow heating-cooling cycle reaching a temperature of $600^{\circ} \mathrm{C}$. It is known that some structures, such as those used for the storage of active (mainly radioactive) thermal wastes, geothermal reservoir engineering etc., can be altered by high temperatures coupled with gas or water pressure. Previous studies have shown that some cracks induced by high temperatures are able to self-heal when they are exposed to a sufficient quantity of water[1, 2]. The rehydration mechanisms correspond mainly to: 1) the precipitation of calcium carbonate in the presence of water and dissolved $\mathrm{CO}_{2} ;$ 2) further rehydration of unhydrated cement paste; 3) newly formed C$\mathrm{S}-\mathrm{H}$ filling cracks in the presence of water. However, the relationship between transport properties and the shape of the distribution of healing products in heat-induced cracks is limited. In an effort to overcome this difficulty, a dedicated test device was used to accurately evaluate the permeability of a heattreated sample, before and after rehydration. The occurrence and degree of rehydration were also complemented by thermogravimetric (ATG) tests and micro-tomography (CT) analysis. In addition to these measurements, a new crack segmentation technique was developed to observe the healing products following the rehydration by $\mathrm{CT}$.

\section{EXPERIMENTAL MATERIALS AND METHOD}

A normalized European mortar with $\mathrm{W} / \mathrm{C}=50 \%$ was used for this study. It comprised normalized sand $(0-4 \mathrm{~mm}$ from Leucate France) and Type II Portland cement (CEM II /B5 (LL-S) 32.5R), which is a mixture containing $65-79 \%$ clinker, $21-35 \%$ calcite and $0-5 \%$ secondary constituents, according to the formulation shown in Table 1. This type of mortar has been widely used in our laboratory for the study of other properties of cement-based materials, such as the role of thermal treatments on its mechanical properties [3, 4], poro-mechanical properties [5] and transport properties under different confining pressures [6, 7]. In addition, this type of mortar can be easily reproduced by other laboratories.

For the ATG and CT tests, a CEMI (52.5R, 95\% clinker) type of cement paste with $\mathrm{W} / \mathrm{C}=50 \%$, matured in limewater for 3 years, was selected. 
Table 1: mortar constituents with $\mathrm{W} / \mathrm{C}=50 \%$

\begin{tabular}{ccc}
\hline Compounds & $\begin{array}{c}\text { Mass } \\
\text { proportion } \\
(\mathrm{Kg})\end{array}$ & $\begin{array}{c}\text { Volume } \\
\text { proportion } \\
(\%)\end{array}$ \\
\hline Normalized sand & 1350 & 58 \\
CEM II & 450 & 16 \\
Water & 225 & 26 \\
\hline
\end{tabular}

\subsection{Sample preparation}

The mortar samples were cylindrical, with a diameter of $37.7 \mathrm{~mm}$ and a length of 60 or $70 \mathrm{~mm}$, and were cored from beams matured in limewater for 3 months, at a constant temperature of $20^{\circ} \mathrm{C}$. For the permeability test, both surfaces of each sample were rectified in order to produce suitably smooth and planar surfaces.

The cement paste cylinders (diameter of $6 \mathrm{~mm}$ and length of $20 \mathrm{~mm}$ ) were cored from $37 \mathrm{~mm}$ diameter cylinders for the preparation of the ATG and CT tests, as shown in Fig. 1.
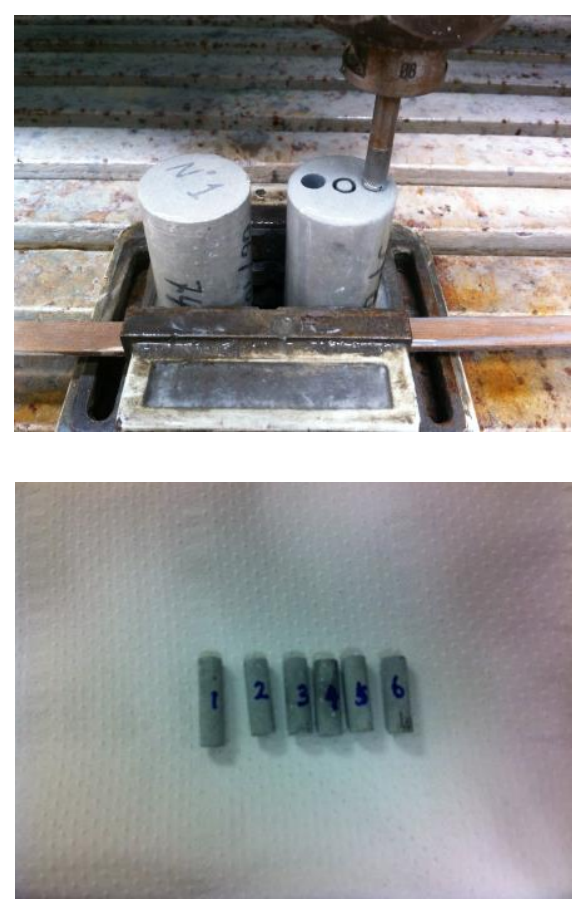

Figure 1. Cylinders for ATG and CT tests
In the following, oven-drying at $105^{\circ} \mathrm{C}$ was used to achieve the reference state, following which a heating-cooling cycle was applied, as shown in Fig. 2. A maximum temperature of $600^{\circ} \mathrm{C}$ was chosen in this study. The heattreated mortars and cement pastes were then immersed in distilled water inside a hermetic chamber (see Fig. 3), and finally subjected to outgassing under vacuum 3 times a day until their mass stabilized. After reaching saturation, the samples were again treated in an oven at $105^{\circ} \mathrm{C}$, until their mass stabilized (this is referred to as the reference state).

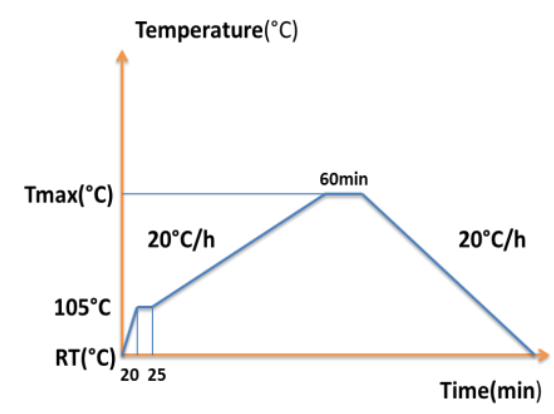

Figure 2. Diagram of the heating-cooling cycle.

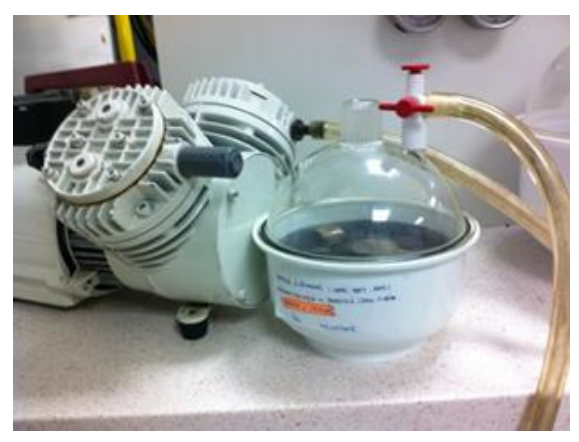

Figure 3. Air-vacuuming of samples after the heatingcooling cycle.

\subsection{Gas and ethanol permeability} measurements before and after rehydration

In order to investigate the influence of 
rehydration, a steady-state gas and ethanol flow was used, following heat treatment, to measure the permeability of the same mortar sample before and after rehydration. During this test, the sample was first placed in a home made pressure-confining cell, placed under constant hydrostatic stress by means of a GILSON pump; a gas or ethanol pressure $\mathrm{P}_{\mathrm{i}}$ was then applied upstream; the downstream pressure $\mathrm{P}_{0}$ was equal to the atmospheric pressure. For the gas permeability measurements, the downstream portion of the flow was monitored with a flowmeter. A detailed description of this setup is presented in Fig. 4.

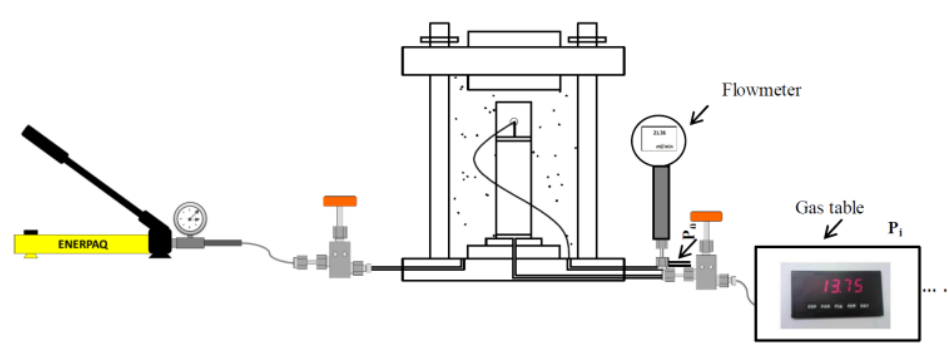

Figure 4. Experimental set-up for gas permeability test under different confining pressures.

From the generalized Darcy law, the gas or liquid (water or ethanol) permeability can be measured directly when a quasi steady-state flow is achieved (i.e. $\mathrm{K}_{\mathrm{gas}} \geq 10^{-20} \mathrm{~m}^{2}$ ). For our samples, the apparent gas permeability in the direction of their length $\mathrm{L}$, is derived from Darcy's law as:

$$
K_{g a s}=\frac{\mu Q_{m}}{A} \frac{2 L P_{i}}{\left(P_{i}^{2}-P_{0}^{2}\right)}
$$

where $\mathrm{K}_{\mathrm{gas}}$ is expressed in $\mathrm{m}^{2}, \mu$ is the dynamic viscosity of the gas: $2.2 \times 10^{-5} \mathrm{~Pa} \cdot \mathrm{s}$ at $20^{\circ} \mathrm{C}$ for Argon, where $\mathrm{P}_{\mathrm{i}}$ takes the values 0.5, 1.0 and $1.5 \mathrm{MPa}$ in the present study, $\mathrm{P}_{0}$ is the atmospheric pressure, and $\mathrm{L}$ and $\mathrm{A}$ represent the length and cross-sectional area of the sample.

The ethanol permeability was also measured under steady-state flow conditions using a constant liquid injection pressure $P_{i}$ equal to $2 \mathrm{MPa}$, as shown in Fig. 5. The measured permeability is considered to be intrinsic. The advantage of this device is that the flow rate can be recorded directly and accurately. When a constant value of $Q_{m}$ is known, the permeability can be expressed as:

$$
K_{\text {ethanol }}=\frac{\mu Q_{m}}{A} \frac{L}{\left(P_{i}-P_{0}\right)}
$$

\subsection{Thermogravimetric analysis (ATG)}

Thermogravimetric analysis (ATG) was made using SETARAM ${ }^{\mathrm{TM}}$ micro scales, the temperature rate increase was $10^{\circ} \mathrm{C} / \mathrm{min}$, until $750^{\circ} \mathrm{C}$. Four test samples in powder form, with masses ranging from $22 \mathrm{mg}$ to $30 \mathrm{mg}$, were selected. These were oven dried at $105^{\circ} \mathrm{C}$, rehydrated at $105^{\circ} \mathrm{C}$, heat-treated at $600^{\circ} \mathrm{C}$ and finally rehydrated at $600^{\circ} \mathrm{C}$.

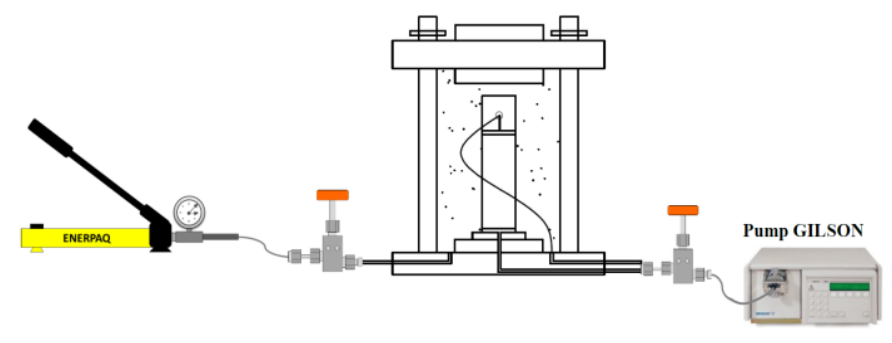

Figure 5. Experimental set-up for the ethanol permeability test under different confining pressures. 


\subsection{X-micro-CT}

High-resolution

micro-tomographic acquisitions were made with identical cement paste samples (diameter of $6 \mathrm{~mm}$, length of $20 \mathrm{~mm}$ ) in three different states: 1) reference state at $105^{\circ} \mathrm{C}$ (prior to heat treatment); 2) after heat-treatment at $\left.600^{\circ} \mathrm{C} ; 3\right)$ after rehydration with distilled water.

X-ray micro-tomography was performed by the Mechanical Laboratory of Lille (LML) using a computerised CT system. Since the resolution achieved during these measurements was $4 \mu \mathrm{m}$, pores or cracks smaller than $4 \mu \mathrm{m}$ could not be detected. As the same sample had to be scanned in three different states (mentioned in section 2.4), the same acquisition parameters (exposure time, voltage, scan direction, tube current and number of slices, etc.) were used. Following these scan measurements, data reconstruction and analysis were performed using the AVIZO v. 9.0 software. Prior to segmentation of the connected pores and cracks (porosity), a median filter was applied, to reduce the influence of noise.However, after median filter, the gray-level value of the same phase, such as porosity or hydration products in different states: (1) reference state; (2) $600^{\circ} \mathrm{C}$ heat-treatment; (3) $600^{\circ} \mathrm{C}$ after rehydration, varies in a relative smaller range due to different constitutions and the effect of median filter, see Fig.6(solide lines). In other word, for the sample in states (1) and (2), gray-level value of peaks of porosity or hydration products dilates and offsets a little extent in the gray-level histogram, compared with the state (3), which is mainly accounting for the different attenuation of $\mathrm{x}$-ray in different states
. Since the same thresholding value of porosity segmentation should be chosen for the three states, we needed to make the gray-level histogram of states (1) and (2) overlap with state (3), see Fig.6(dotted line). After the alignment of the grey-level histogram, interactive thresholding is applied to segment the porosity of state(3) at first, and in the following, the obtained thresholding value is thus used to segment the porosity in states (1) and (2).In the following, a series of adjustments (envelope, erosion, and various arithmetic operations) was applied using AVIZO, to improve the geometry of the connected and non-connected cracks.Finally, the rehydration products could be separated and clearly observed by subtracting the reconstruction after rehydration and the reconstruction after heat-treatment at $600^{\circ} \mathrm{C}$.

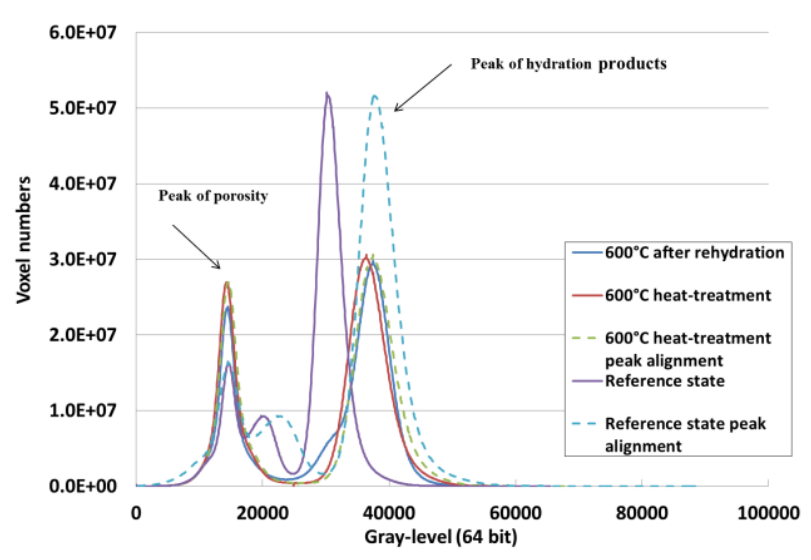

Figure6. Correction of grey-level histograms for the $105^{\circ} \mathrm{C}$ oven-dried and $600^{\circ} \mathrm{C}$ heat-treated states.

\section{RESULTS AND DISCUSSION}

The tests described in the previous section are discussed in the following in which we compare the influence of temperature and 
rehydration, measured in terms of the gas and ethanol permeabilities of different mortar samples.

\subsection{Relationships between heat-treatment and hydrostatic permeability}

The sample Y-MP-12 $105^{\circ} \mathrm{C}$ was chosen as the reference state with the purpose to compare with sample YM II $48600^{\circ} \mathrm{C}$ (after heat treatment and following rehydration). Hydrostatic loading (Pc), from 5 to $40 \mathrm{MPa}$, was applied to both samples. Fig. 7a plots the value of $\mathrm{K}\left(\mathrm{Pc}, \quad \mathrm{T}^{\circ} \mathrm{C}\right) / \mathrm{K}\left(5 \mathrm{MPa}, \mathrm{T}^{\circ} \mathrm{C}\right)$ as a function of $\mathrm{Pc}$, clearly showing that the mortar at the reference state is not very sensitive to $\mathrm{Pc}$, with values of $\mathrm{K}_{\mathrm{gas}}$ ranging from $1.65 \times 10^{-}$ 17 to $9.95 \times 10^{-18} \mathrm{~m}^{2}$. It should be added that during unloading, there is a low permeability hysteresis. These two phenomena confirm that the reference sample is not affected by cracks. This is not the case of the heated sample which reveals a high sensitivity to confining pressure (Fig.7a). This is directly related to the degree of heat treatment damage that can induce two parallel effects : cracking (i.e. high sensitivity to $\mathrm{Pc}$ ) and pore widening (i.e. strong increase in permeability compared to the reference value). $\mathrm{K}_{\mathrm{gas}}$ is now ranging from $3.5410^{-15}$ to $5.910^{-16} \mathrm{~m}^{2}$. At $\mathrm{Pc}=5 \mathrm{MPa}$, the value of $\mathrm{K}$ is 200 times greater than that measured for the $105^{\circ} \mathrm{C}$ sample. During unloading there is now a strong permeability hysteresis. To simplify it can be supposed that the sensitivity to Pc, coupled with this hysteresis, is due to irreversible closure of cracks. It is thus interesting to observe the same results which are shown in Fig.7b with a different presentation. In this case we have plotted the values of $\mathrm{K}\left(\mathrm{Pc}, \mathrm{T}^{\circ} \mathrm{C}\right) / \mathrm{K}\left(5 \mathrm{MPa}, 105^{\circ} \mathrm{C}\right)$. It confirms that during unloading, the sample's permeability (YM II $48600^{\circ} \mathrm{C}$ ) is relatively insensitive to confining pressure (irreversibility of crack closure) and shows that after a complete unloading the value of $\mathrm{K}$ is still 50 times greater than that of the reference sample. This difference would be due to pore widening as the cracks are supposed to remain closed. This was confirmed by the subsequent CT results. This is however a simplified assumption as a (almost partial) pore collapse can not be excluded for the heated material.

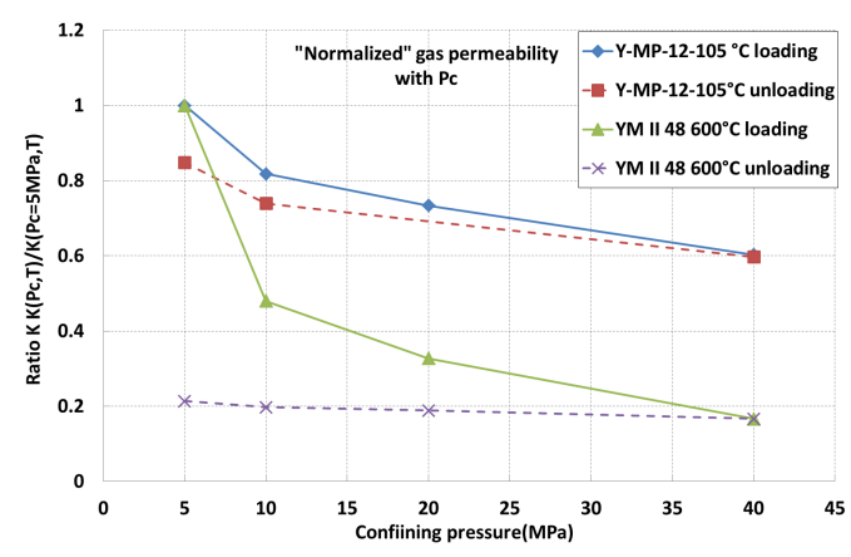

Figure 7a. Influence of confining pressure on the gas permeability ratio $\mathrm{K}(\mathrm{Pc}, \mathrm{T}) / \mathrm{K}(\mathrm{Pc}=5 \mathrm{MPa}, \mathrm{T})$.

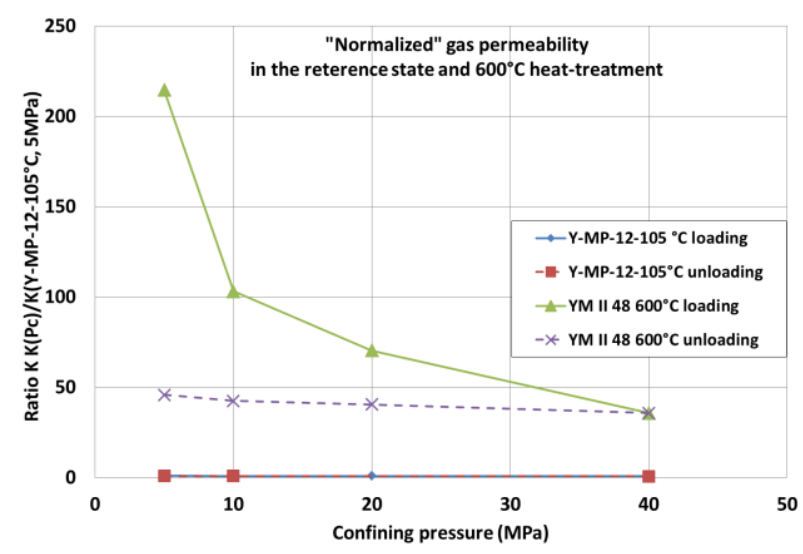

Figure 7b Influence of confining pressure on the gas permeability ratio $\mathrm{K}(\mathrm{Pc}, \mathrm{T}) / \mathrm{K}\left(\mathrm{Pc}=5 \mathrm{MPa}, 105^{\circ} \mathrm{C}\right)$. 


\subsection{Relationship between rehydration and hydrostatic permeability}

Following the measurement of its gas permeability, sample YM II $48600^{\circ} \mathrm{C}$ was saturated in distilled water, in order to determine the extent to which it could be rehydrated. As the gas and ethanol permeabilities of mortar have been shown to be of the same order (F. Skoczylas et al. [8]), here they were also measured in order to identify the influence of rehydration on permeability. Fig. 8 shows that after rehydration, the ethanol permeability of sample YM II $48,600^{\circ} \mathrm{C}$ varies between $4.0 \times 10^{-18}$ and $8.0 \times 10^{-18} \mathrm{~m}^{2}$ during the loading stage, in agreement with the permeability of the reference state sample at $105^{\circ} \mathrm{C}$ (also in Fig.8a); the value of gas permeability has the same tendency with ethanol permeability, ranging from $1.5 \times 10^{-17}$ and $2.1 \times 10^{-17} \mathrm{~m}^{2}$. When these results are compared to the gas permeability measured prior to rehydration (of the order of $10^{-15} \mathrm{~m}^{2}$ ), it is clear that a selfhealing process occurs during saturation. This behavior was also revealed by the microtomographic measurements (Fig.10a): hydration products are seen to plug the heatinduced cracks, thereby blocking the transport of liquid. It is worth mentioning that, after rehydration, values of both ethanol and gas permeability do not change significantly (about $4.0 \times 10^{-18} \mathrm{~m}^{2}$ and $1.5 \times 10^{-18} \mathrm{~m}^{2}$, respectively) with the unloading of confining pressure, which is mainly because the irreversible closure of micro-cracks due to former confing pressure.

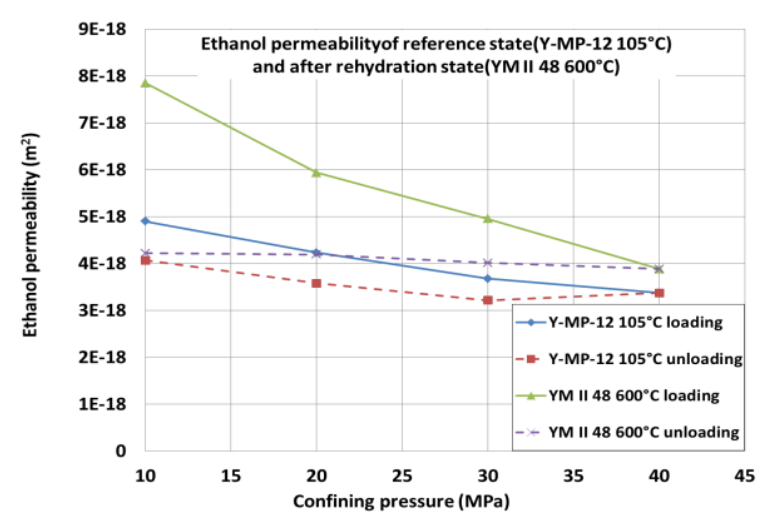

(a)

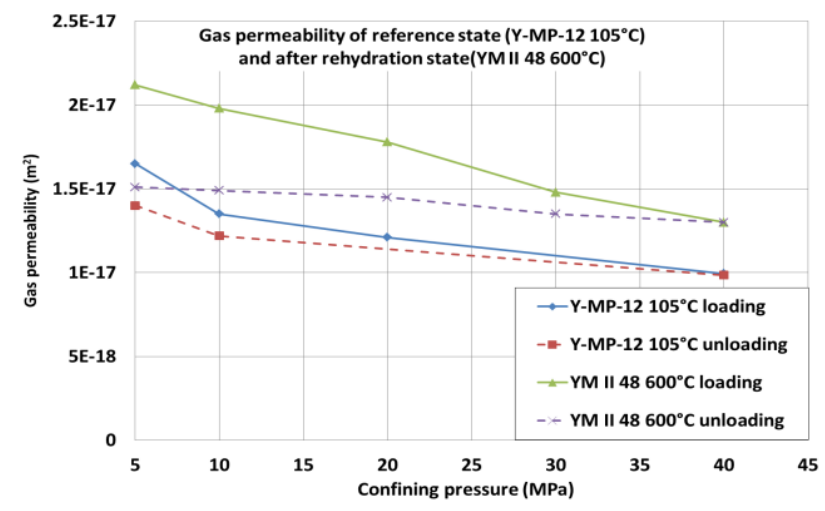

(b)

Figure 8 Ethanol permeability of $105^{\circ} \mathrm{C}$ oven-dried, and $600^{\circ} \mathrm{C}$ rehydrated samples during confining pressure loading and unloading.

\subsection{ATG/DTG results}

Fig. 9a and $9 \mathrm{~b}$ present the results of the ATG/DTG tests made on cement paste, as described in section 2.3. The comparison between $600^{\circ} \mathrm{C}$ heat treated and $105^{\circ} \mathrm{C}$ cement paste can be analysed in Fig.9a. No significant loss of mass (up to $600^{\circ} \mathrm{C}$ ) is observed for the heat treated sample which reveals that the decomposition of calcium hydroxide $(\mathrm{CH})$ and of C-H-S was almost complete. In Fig. $9 \mathrm{~b}$ can be observed the results for the $600^{\circ} \mathrm{C}$ heat treated sample after rehydration and $105^{\circ} \mathrm{C}$ sample. This clearly shows that there is now 
no significant difference between the ATG/DTG profiles of both samples. This outcome confirms that rehydration occurs and that the products obtained are mainly $\mathrm{C}-\mathrm{S}-\mathrm{H}$ and $\mathrm{CH}$. These results are ewell correlated with the significant improvement in permeability described in section 3.2.

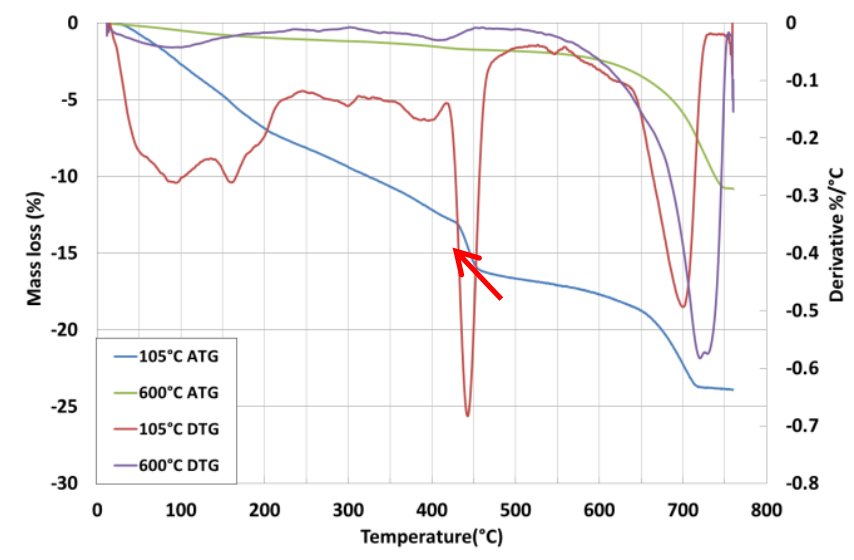

Figure 9a Comparison of ATG/DTG profiles for the $105^{\circ} \mathrm{C}$ oven-dried, and $600^{\circ} \mathrm{C}$ heat-treated samples.

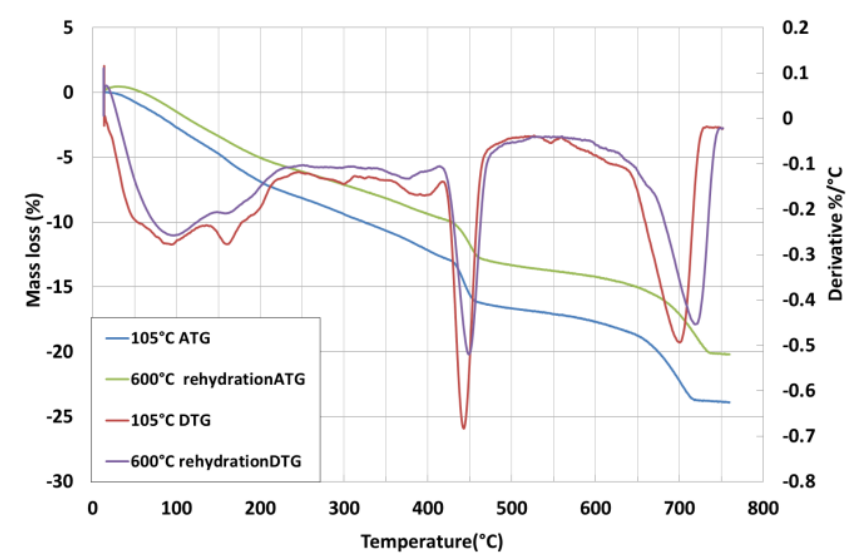

Figure 9b Comparison of ATG/DTG profiles for the $105^{\circ} \mathrm{C}$ oven-dried and $600^{\circ} \mathrm{C}$ heat-treated samples, after rehydration

\subsection{Micro-tomography (CT) results}

The morphology of the cracks following $600^{\circ} \mathrm{C}$ heat-treatment and rehydration are shown in the form of segments in Fig. 10a and 10b, respectively. Different colors represent different pore sizes. By subtracting the images Fig.10b (after rehydration) and $10 \mathrm{a}\left(600^{\circ} \mathrm{C}\right.$ heat-treated before rehydration), the amount of rehydration products could be clearly separated, see Fig.11a (presenting the formed rehydration products). Again, in Fig.10a, it can be seen that a heat-induced crack has provided access to the initial occlusive pores, which is confirmed by the sharp increase in gas permeability of the $600^{\circ} \mathrm{C}$ heat-treated sample in the section 3.1. However, in Fig.11(a-d), healing products, which are mainly newlyformed $\mathrm{C}-\mathrm{S}-\mathrm{H}$ and calcium carbonate crystallization, filled the heat-induced cracks, even blocked the access of fluide transport and therefore greatly reduced the permeability of the heat-teated mortar. This exactly explains the reduction of gas/ethanol permeability after rehydration(results in section 3.2). 


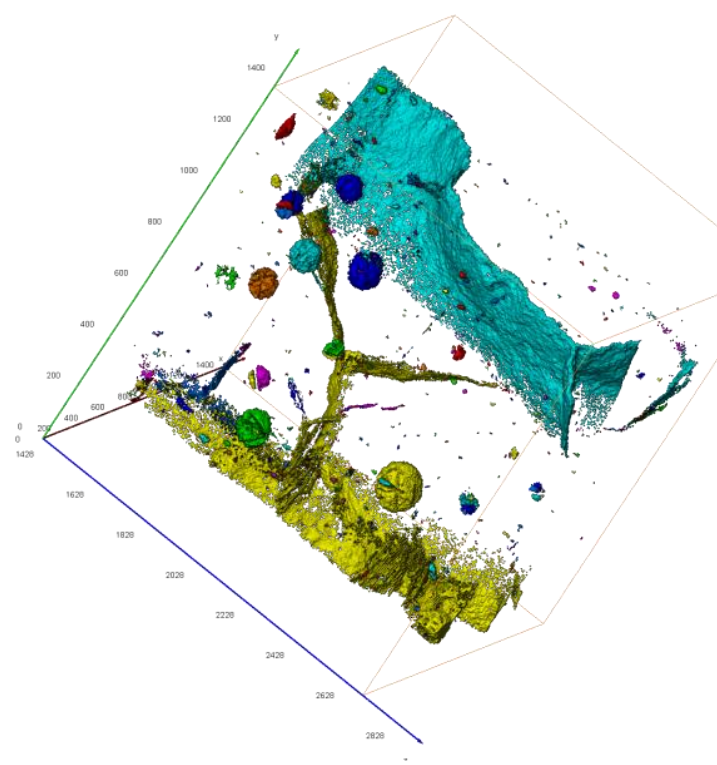

a)

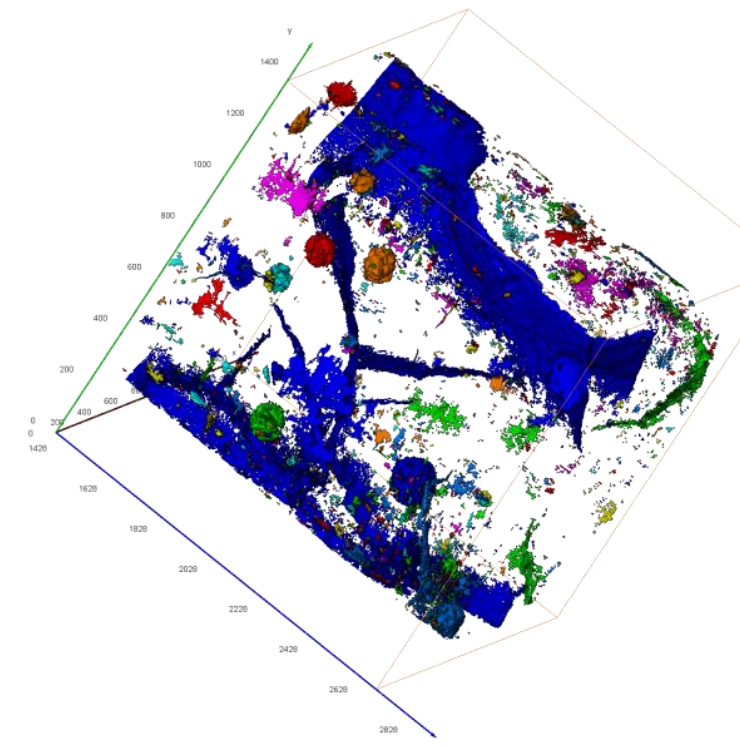

b)Figure 10 a) Crack segmentation of the $600^{\circ} \mathrm{C}$ heattreated sample; b) crack segmentation of the $600^{\circ} \mathrm{C}$, rehydrated sample.

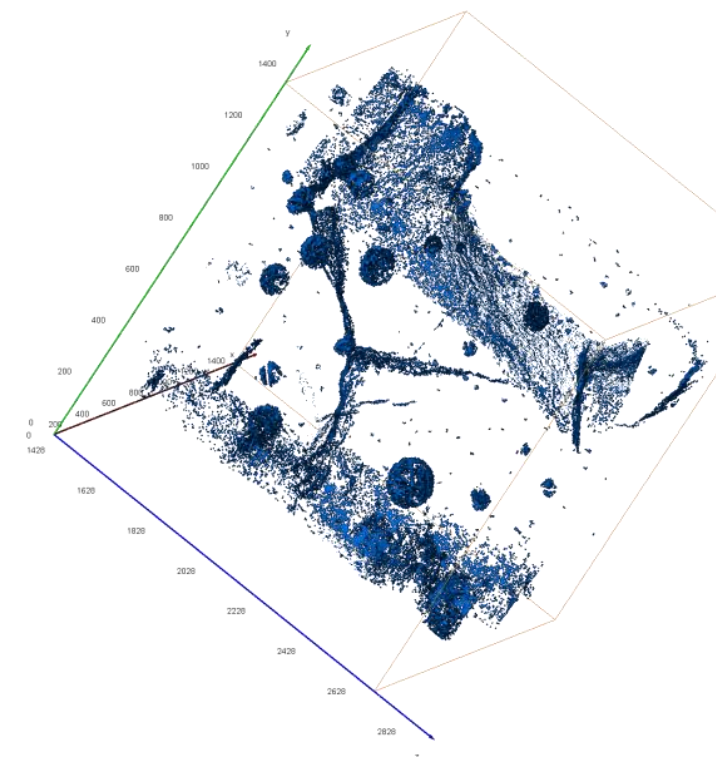

a)

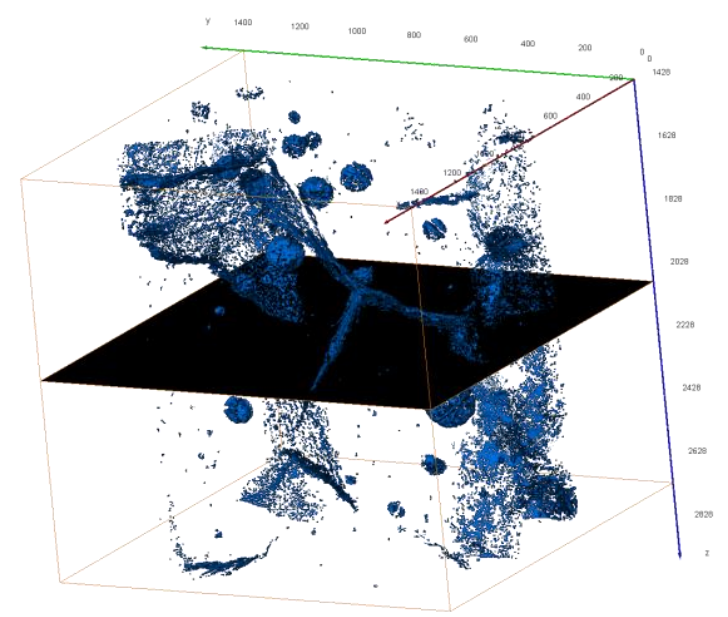

b) 


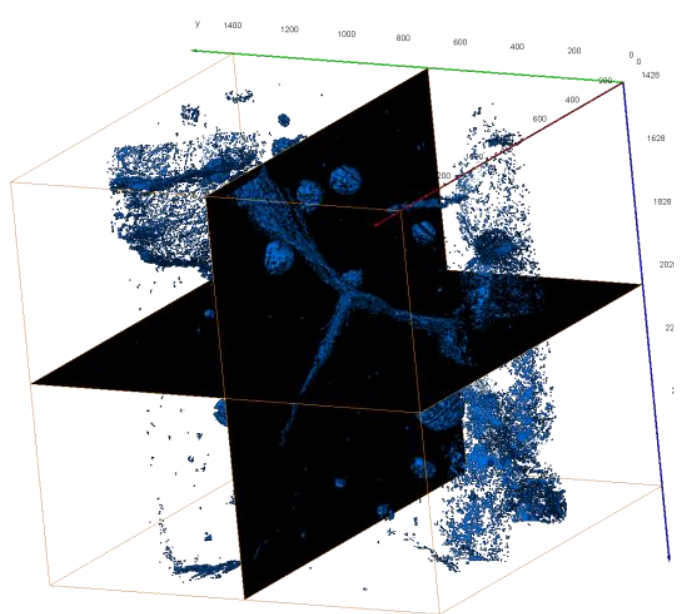

c)

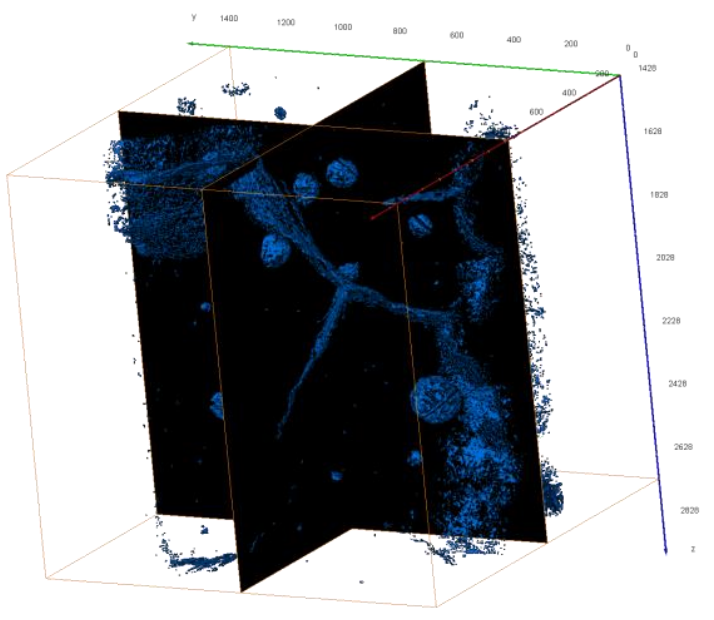

d)

Figure 11 Shape of the distribution of rehydrati products in a 3D profile.

\section{CONCLUSION}

The tests described in this study show that the gas permeability of normalized mortar is approximately $10^{-15} \mathrm{~m}^{2}$ after heat-treatment at $600^{\circ} \mathrm{C}$. Following rehydration, the mortar's ethanol permeability lies in the range between $10^{-17}$ and $10^{-18} \mathrm{~m}^{2}$, which is very close to the value of intact gas permeability in $105^{\circ} \mathrm{C}$ $\left(10^{-18}-10^{-17} \mathrm{~m}^{2}\right)$. This is due mainly to selfhealing, which occurs in both macro and micro heat-treated cracks when they are saturated with water. During the preceding gas permeability cycle, an increase in confining pressure also contributes to the irreversible closure of some cracks. Finally, a good correlation is found between the results of ATG, CT and (gas, ethanol) permeability measurements, all of which reveal a rehydration phenomenon occurring in heatinduced cracks. CT is shown to be an extremely useful, non-destructive technique when studying the rehydration of cementitious materials. It also makes it possible to learn more about the morphology distribution of the rehydration products. In a future study, we plan to report on the quantification of crack and pore size distributions, as well as the volume of rehydration products.

\section{REFERENCES}

1. Lin, W.-M., T. Lin, and L. Powers-Couche, Microstructures of fire-damaged concrete. ACI Materials Journal, 1996. 93(3).

2. Poon, C.-S., et al., Strength and durability recovery of fire-damaged concrete after postfire-curing. Cement and Concrete Research, 2001. 31(9): p. 1307-1318.

3. Yurtdas, I., N. Burlion, and F. Skoczylas, Experimental characterisation of the drying effect on uniaxial mechanical behaviour of mortar. Materials and structures, 2004. 37(3): p. 170-176.

4. Yurtdas, I., N. Burlion, and F. Skoczylas, Triaxial mechanical behaviour of mortar: Effects of drying. Cement and Concrete Research, 2004. 34(7): p. 1131-1143. 
5. Chen, X.-T., et al., Effect of heat-treatment and hydrostatic loading upon the poro-elastic properties of a mortar. Cement and Concrete Research, 2009. 39(3): p. 195-205.

6. Chen, X.-t., et al., Coupled transport and poromechanical properties of a heat-treated mortar under confinement. Cement and Concrete Research, 2013. 49: p. 10-20.

7. Chen, X.-T., et al., Experimental and micromechanical analysis of the mechanical and transport properties of mortar containing heatinduced micro-cracks. Cement and Concrete Composites, 2010. 32(9): p. 678-685.

8. Loosveldt, H., Z. Lafhaj, and F. Skoczylas, Experimental study of gas and liquid permeability of a mortar. Cement and Concrete Research, 2002. 32(9): p. 1357-1363. 